\title{
FAITH-BASED TECHNOLOGY DURING PRE- AND POST-COVID-19 PANDEMIC
}

\author{
Fatima Hasnain \\ MPhil Scholar, Pakistan Institute of Development Economics \\ fatimahasnain5@yahoo.com
}

\begin{abstract}
Shaheer Ellahi Khan
Associate Professor, Health Services Academy, Ministry of National Health Services, Regulations and Coordination

shaheerellahi@hotmail.com
\end{abstract}

\author{
Mian Ali Kamran Baba \\ MPhil Scholar, Pakistan Institute of Development Economics \\ akamran1000@gmail.com
}

\begin{abstract}
This study aims to document how technology and religion have co-existed, before and after the Covid-19 pandemic. The present qualitative study was conducted in the Shi'a community of sector G-11, Islamabad using an exploratory approach; semi-structured interviews and participant observation were used as tools to collect data. The respondents were found to adopt and adapt to the technological advances to maintain their religious affairs and blend their traditional roots with the emerging technological colours. Ritual $(s)$ of household-based religious gatherings-the majalis (plural for majlis)-have urged the women of the Shi'a-Islamic community to explore modern technological instruments, and to apply them to their daily routine with the help of different social media platforms. After the outbreak of COVID-19 pandemic and a nationwide lockdown, technology became the bridge to connect people and let them maintain their lives; the same was observed for the continuance of Shi'a rituals in this particular community. However, with the advent of a new technological age, this moderntraditional blend also threatens the originality of religious belief(s) during their transmission through technology. Hence, this study presents how technology penetrates into Shi'a women's religious lives before and after the Covid-19 pandemic, and how it may threaten the originality of their beliefs and rituals.
\end{abstract}

Keywords: Faith based technology; Shi'a community; Women empowerment; Majlis; Exploratory research; Online rituals; Covid-19

\section{INTRODUCTION}

The visage of the Shi'a faith and rituals, the majlis, has been practiced since the times when Islam was budding in Arab soil. Practiced by the Arabs before the advent of Islam, and during the initial days of the nourishment of Islam by the Prophet Muhammad (pbuh), the majlis or the sitting, has been an eminent tradition. The contemporary Shi'a majalis are said to be the lineal continuity of the ones set up by Imam Jafar Sadiq (a.s) in the beginning of the Abbasid era, when the Shi'a were strictly barred from conducting any relevant activities. However, it was the practice of Hazrat Zainab (s.a), Imam Ali Ibn Hussain Zain-ul-Abideen (a.s), and Um-ul-Banin (s.a) of organizing sermons and gatherings to spread the message of Karbala in Damascus and Madina (Howarth, 2005). Shi'a majlis contributes to constructing the identity and framing the cognition of women who actively participate in these gatherings. It also directs the influential factors of women's lives, including their knowledge, decisionmaking power, health dynamics, success, matters related to marriage and divorce, gender diffusion in domestic and communal activities, and most importantly, social cohesion and networking.

Rituals on a whole do not only serve as a divine cause, but also make the religious practitioners express their hearts and souls out through a 'soft medium of metaphysicality'. Their faith and spiritual 
connections provide them with a transcending experience that does not require any tangible equipment, rather their inner selves. As illustrated by Karakas et al., (2015) 'connectedness' is an important aspect of spirituality and all spiritual/faith-based actions that an individual or a community perform. The connectedness is with the self, with other human beings, and with a higher power. The key features of this wing of spirituality include friendship, trust, sensitivity to other people's matters and a sense of belonging (Karakas, Sarigollu, \& Kavas, 2015).

Connectedness can be regarded as a common attribute between religion and technology. Information technology is "any computer-based tool used by people to work with information and support information-processing needs of an organization" (Haag et al., 1998). As religious movements began to submerge with technology and started to become online with the flow of Internet in mid1990s, people started to develop a spiritual connection with the usage of World Wide Web. It was also an efficient tool to enhance social connectedness through electronic mailing, instant text-messages, Facebook and other media to reach out to their family and friends throughout the globe (Helland, 2015). WhatsApp is another contemporary technological tool widely used (and well-known to the readers of this text as well). It allows the people to communicate effectively and express themselves through text messages, voice calls as well as video calls. Hence, the array of connectedness through WhatsApp is widespread.

The Shi'a women have taken strong support of the recent and modern technological tools in carrying out their rituals and organizing faith-based gatherings within their community. Faith of Shi'a women has equipped them with understanding and using modern technological tools such as WhatsApp, Facebook, and other instruments such as speakers and microphones. The Covid-19 pandemic has further capacitated them to continue with their rituals while making sufficient use of technology. The use of technology during the pandemic has played a positive role for the community to continue with their activities. On the other hand, certain drawbacks of involving technology into rituals also appear on the list.

This paper aims to document the ritualistic use of technology by this specific community. It aims to explore how the Shi'a-Islamic women in the G-11 sector of Islamabad use technology for the purpose of organising religious gatherings; to see how they maintain their social networks already created in their existing spiritual capital; how the integration of technology in their lives has become an agency for them; and what negative impacts are posed to their religious, social, and moral values. It also documents how this community have exhibited a sudden adaptation to the use of technology during Covid-19 lockdown for the resumption of their religious activities. Being scientific research, it highlights both the merits and demerits of this situation and the way it has impacted the religious and ritualistic lives of Shi'a women in Islamabad.

\section{REVIEW OF LITERATURE}

It is notable how technology has marked the lives of Muslims around the world, encompassing their religious thoughts, preaching content and styles, issuance of fatwas, and maintaining their relations as a global community. Where Islamic messages and education was limited to print media in the past, today SNSs have emerged to provide a greater platform that have enabled people to communicate instantly through online services such as Skype and electronic mails. Both synchronous and asynchronous communicative tools have encouraged people to share their religious beliefs across social media. Applications such as Paltalk and Yahoo Messenger are examples of such forums (Hosseini et al., 2014). Some websites like 'Online Islam' provided a platform for 'one-stop shopping' for the Muslims, which led to the emergence of 'Facebook fatwas' or 'F-fatwas'. Special occasions and holy months of the Islamic religion create hype in posting and accessing different religious news, activities, as well as any related religious instructions. Promoting the social capital, networking, and connectedness among the Muslim users of technology, social media have enabled them to mobilise and unite for mutual religious causes. Most of the Muslims active on social media live in the Western societies. The proselytizing attempts are extremely successful where many Muslims make use of technology to learn about Islam and then embrace it by making their own online documentation. Many Sufi orders have also been noted to be technologically active in performing activities of spiritual cleansing now (Ibahrine, 2014).

Similarly, CommuniTree was an online social-networking system/site (SNS) based in California, where people posted messages and responded through commenting on a bulletin board, including a major portion for religious communication. This form of online religious activity opposed 
the 'traditional, hierarchical forms of religious expression and community' (see Helland 2015, p.6) and promoted synchronous communication to provide every member of the community to converge and participate (Helland, 2015).

Technology and religion can also be seen together in Indonesia through WhatsApp. 'One Day One Juz', or ODOJ, is part of an Islamic movement in which the preachers encourage people to complete one $J u z$, or part, of the Quran in one day on WhatsApp. This activity indicates how a mobile phone device has become a 'domesticated, Indonesianised, and Islamised' activity. The main proponents of the ODOJ movement consider WhatsApp as their main medium of developing Quranic influence on their target population (Nisa, 2018). Online technology has helped scholars in missionary activities as it becomes difficult to meet individually with many people. Similarly, other tools such as mailing lists, YouTube, blogs etc. are other examples of technology used for religious purposes (Nurdin $\&$ Rusli, 2012). Muslim communities around the world have learned ways of pronouncing Quranic words properly; attending online Quranic classes is easier for many as compared to travelling towards the venue itself. Such facilities are especially serving the Muslim communities residing in non-Muslim countries (Mahdi \& Adamu, 2015).

According to Saifee et al. (2012), media is generously used to disseminate religious messages and impart education to the younger generation. It may be through electronic media, print media, social media, and even online libraries. These forums assist and facilitate the people in accessing religious, particularly Islamic educational material. Some of the prominent faith-based international and national TV channels include MTA Muslim TV, Peace TV, Hidayat TV (Shi'a Channel), and Ahlebait TV (Shi'a Channel). These technological tools serve in spreading religious messages and education to the audience (Saifee et al., 2012). Islamic websites particularly designed to disseminate the orders of Allah with respect to the teachings of the Prophet Muhammad (PBUH) have become frequent in today's era. Most Islamic websites constitute Islamic online services such as blogs, educational trainings, community support programs and capacity building, online marriage platforms, relief, and donation activities, and contact and discussion with scholars regarding various life matters (Hosseini et al., 2014). SNSs that are used for publicizing and teaching purposes constitute a major portion of different Islamic topics, according to a study. Out of $50 \%$ of the topics discussed, $40 \%$ were Islamic, including Quran, Sunnah, Fatwas ${ }^{[i]}$, Tafseer, proofs from the Quran and inquiries about various Islamic websites. It also concluded that $78 \%$ of Islamic information was increased through these social networking sites (Nassar et al., 2013, pp.15-16).

Recently in 2006, the Tibetan Diaspora as well as the non-Tibetan(s) residing anywhere in the world began to utilise the Internet with one of the largest wireless networks that was established in Northern India. One of the most significant outcomes of this virtual space was their enhanced connectedness with their religious scholars and monks. A Buddhist residing in another part of the world could seek religious learning, opt for related online courses, and join the religious events taking place in their religious capital from across the seas for the first time in their religious history. Tibetan Diaspora not only remained connected with their religious community over the online globe, but also kept their identities and traditions intact that were the very essence of their faith. The online rituals, sacred texts and lamas were all available for the Tibetan community around the globe (Helland, 2015).

Technology is the new centre to conduct faith-based gatherings. As stated by Mr. Ahmed Fairiz, the owner of 'Recite Lab' in Kuala-Lumpur, the solution to the contemporary religious disconnection in societies is technology. However, some instances also state the opposite as found in the present study; the Uighar Muslim community of China for example. The authority in power uses technological tools such as facial-identification camera(s), surveillance of information fed in their online system(s) etc. These are some virtual constraints to inhibit their religious movements (McSweeney, 2019).

The introduction of technology has encouraged people towards freedom of expression, innovative activities, and sharing information and material that might be related to some other individuals' personal life. Other factors such as pornography, misleading information, cyber-bullying, and blasphemous material also flower from open access to technology today. Islamic values face a risk in many parts of the world today due to the access to the evils modern technology has provided, especially in the moral and spiritual upbringing of children and youngsters. Other threats include the intermingling of the reality and fiction, considering false information as the teachings of Islam. Several divorces have been reported due to the misuse of technology, as well as un-Islamic relationships and 
extra-marital affairs (Shehu et al., 2017). Cyber-bullying, misrepresentation, and false identities of individuals add to the possible threats while communicating online. Where Islam itself endorses to maintain the privacy of every individual, technology has played a negative role in breaching privacies by recording and maintaining personal data, messages, and alteration of messages in some cases (Hosseini et al., 2014).

Nevertheless, it is an evident phenomenon how faith-based use of technology impacts the lives of religious communities (in this case, Muslims). Social media have enabled them to connect, mobilise and unite in mutual and religious grounds (Ibahrine, 2014). Moreover, the era of pandemic has further promoted technology use including WhatsApp, YouTube, and Facebook; a study concluded that users ranging from patients and doctors to teachers, students, and the general public reported to have used technology more during the pandemic. Some of the effects of this use included reduced spread of the Coronavirus outbreak, continuity of education with safety measures, increased productivity, and maintenance of social connections (Vargo, Zhu, Benwell, \& Yan, 2020).

\section{MATERIALS AND METHODS}

Methodology: This qualitative research follows an exploratory approach, where the data were analysed through thematic analysis and verbatims were quoted to further elaborate the evidence being presented in the data section. The research is a case study of the sector G-11 of Islamabad. Rapport: Religion is a delicate and sensitive arena of one's life, disgracing which may lead to failure in acquiring the desired results of the research. Therefore, it was necessary to build a rapport, which was done through punctuality and regular attendance of the majalis and interaction with the respondents. The women were very welcoming and open to the cause; they interacted and assimilated well in a shorter period of time. Methods and tools: The data were collected through interviews and observation after obtaining verbal informed consents from the respondents. Participant observation and semi-structured interviews were used as the tools. Interview guides were used for a pre-sketch of the interviews to be conducted. Key Informant was also contacted to get into the schedules of the majalis. The WhatsApp group was used as a consistent tool to collect data about the research. Semi-structured interviews: Two interview guides were constructed for semi-structured interviews, each for an organiser and the attendee women. The interview guide was constructed in English, while the interviews were conducted in Urdu language to make it easier for the respondents to communicate. After obtaining verbal consents and informing them about the purpose of the study, their interviews were recorded using mobile recorder (solely for the purpose of transcription as per the respondents' consent). WhatsApp group: A closed WhatsApp group, named Kanizan-e-Um-e-Kulsoom, or the servants of Um-e-Kulsoom, was active in the community to update everyone about the status of the majalis. It was also operated for other purposes of the community, such as small talks or current updates within the closed members of the local Shi'a community. Before the outbreak of Covid-19, the group served as a platform for religious talks, selling of certain products, or interpersonal chitchats. However, during the Covid-19 lockdown, women were actively participating in the group for their religious activities as they were unable to interact physically. Covid-19 updates and health emergency information were constantly shared online to facilitate the community through technology. The researcher joined the group in order to carry out observational data collection and to catch-up with the upcoming majalis of G-11. Facebook was another instrument for observation of the activities of the Shi'a women. Key informant: A key informant was contacted to get access to the areas of information. The woman was a graduate, who was active in updating the WhatsApp group about the recent schedules of the upcoming majalis. She was informed about the research and its objectives, after which she agreed to help for the cause and appreciated the effort. Sampling: Stratified Random sampling was selected as the sampling technique. The randomly selected data were stratified into 2 categories to obtain diverse perspectives from both standpoints, i.e. the Organisers and the Attendees. This helped in understanding and documenting how the respondents were able to adapt with technology, whether they were the hosts or the audience as both required varying technological requirements. Study locale: The selected locale for the research was the sector G-11 of Islamabad - the Capital of Pakistan. An Imam bargah, named as 'Bargah-e-Um-eKulsoom' is established in G-11/2, where most of the activities of the local Shi'a community take place. 


\section{RESULTS AND DISCUSSIONS}

Themes have been extracted to further organise and compose the data, which will lead to the deduction of the desired outcomes. The respondents have been mentioned with pseudonyms. The following results were achieved in this study:

\section{Use of technological instruments}

During the setting of the gathering, a microphone is arranged along with a microphone-stand, connected with a sound-system placed at a corner of the room. The reciters and orators use the device to deliver their religious chants (nohas, manqabats or soz) and sermons respectively. The sound-system is pre-set as per the choice of the organiser. Depending upon the availability of resources, some organisers utilise a cordless microphone while others set up the wiring system. It is not necessary for them to learn to operate these systems, yet they do so to ensure the best of their deliverance in organising a faith-based setting. Moreover, many women who attended the gatherings were also observed to drive their own cars for the sole purpose of their mobility regarding the Shi'a majalis. Due to owning their personal mode of conveyance, it also served in enhancing their interpersonal relations and socialisation skills as they offered other women of the community transport to their respective homes. Not to forget, the mobile phones are key technical devices that every member of this community has learnt to operate to follow up with the relevant religious updates on their mutual WhatsApp group.

\section{Techno-religious connectedness}

Technology has long been among the most prominent methods to enhance connectedness among people coming from various ethnic, social, and religious backgrounds. The era of Industrialisation was the byproduct of rapid industrial productions, later replaced by the age of information and technology. Globalisation is the very main outcome of this information technology as well as an off shoot of everything that is 'soft and online'. The nations and economies around the globe have interconnected using technology and its various applications and tools.

The Shi'a women of the sector G-11 have made a 'techno-religious' platform where every member of the community interacts with one another, discussing and sharing information based on their common religious views. The members come from various economic and social strata, yet united by their religion at a technological platform. Their sensitivity to each other's personal matters sparks up when they connect without even knowing them personally. Their intangible views make them a single community through an intangible technological tool. Even more, this technological interaction brings them closer when they physically meet in the majalis. Their gestures of friendship and a collective sense of belonging to a single community make them connected, regardless of the social and economic strata they belong to.

Technology has been found to be deeply integrated within the religious culture of the Shi'a women. The WhatsApp group established by the Shi'a community under study is one of the prominent types of evidence. The women are connected on the basis of their religious beliefs, yet they make use of it for various matters of their lives including marriages, economic opportunities, academic achievements of their children, sharing of religious information and remembrance of religious events, publicity of upcoming religious gatherings within the community, updates regarding birth or demise of any community member, informing others about somebody's illness and health issues and recovery from illness, news updates regarding global current affairs, chit-chatting with each other and gossiping about any recent dispute or conflict among any of the community members. It also serves as a chance for them to enjoy and have a leisure time with each other and to joke around. This contributed a major share in enhancing social cohesion and networking among the women of the community and their relationship as a common religious community, giving a great boost to their local spiritual capital.

According to the theory presented by Theodore Roosevelt Malloch (2010), the three categories that fall under Spiritual capital are Faith, Courage, and Forgiveness, which arise because of the spiritual connections and associations in one's life. The spiritual capital carries immense importance in boosting up the moral virtues, which has led to a high success rate in some prominent international business companies, such as Phillips International. The CEO of the company aimed to distribute specialised knowledge through establishing a publishing empire and took off with the courageous start of a little 
investment. The use of technology was imperative where the establishment of the company was based on a virtue of spiritual capital (Malloch, 2010)

The women also follow religious pages on Facebook and like the recent posts on any religious update, serving as a source of religious information. Furthermore, they share YouTube and Facebook links for religious videos or religious updates on the common WhatsApp group. They stay connected by receiving and sharing important updates regarding their religious scholars and Shi'a zakirs (orators) all over Pakistan as well as around the world, particularly Iran (the only official Shi'a state).

These instances of unification on the basis of common religious grounds while making sufficient use of technology are consistent with the studies conducted by Mohammed Ibahrine (2014) and Helland (2015), as they elaborate how virtual spaces had enhanced "connectedness" within religious communities as well as with their religious leaders. Social media have exhibited proven examples of mobilising and empowering religious communities (Helland, 2015; Ibahrine, 2014).

\section{Virtual religiosity - modern approach to traditions}

Technology enables its users to carry forward their professional meetings, conduct webinars and address global as well as local emerging issues in all kinds of fields; it has also enabled the religious groups to adopt a modern and contemporary approach to reach out to their traditional roots. The Shi'a community of women in this sector practised their religiosity virtually. Despite conducting majalis in their respective houses as well as in the Imam bargah, they make use of the technology round the clock to share their religious feelings and expressions and enhance their religiosity, referred to as 'online religion' by Helland (2016). The power of sharing religious information is not only limited to mere reading or feeling the texts/voice notes/video recordings; rather it is a key mobiliser to actualise what is being spread on the online group. The moment a religious text is shared mentioning a religious act, a special prayer to be offered in a special religiously marked night, the recitation of any specific dua or supplication, or any section of the Holy Quran ${ }^{\mathrm{ii}}$, the women begin to actualise by performing these rituals. They may share links that take them virtually to the shrine of one of the most prominent Islamic personality, Imam Hussain (a.s) - the son of Imam Ali (a.s), in the city of Karbala, Iraq. By viewing the shrine in a live streaming, they feel as if they were present there, praying to be able to visit the sacred shrine.

This blend of the modern era with their indigenous roots encourages them to adapt to the rapidly evolving discourses of the new age and keep connected with their roots while obliging to their daily routines. As their online rituals may be carried out throughout the day and night, they remain satisfied with their religious commitments along with their domestic responsibilities. A similar case to this was the utilisation of an application named 'Second Life', where the religious groups belonging to Jewish, Christian, Buddhist, Muslim clusters may carry out their religious practices and rituals without any bodily involvement in the real-life scenario. This virtual space allows them to connect with their religious symbols while living their social lives simultaneously (Radde-Antweiler, 2008).

Virtual practices of religious traditions over the online forums have been observed in the Tibetan Diaspora, as studied by Helland (2015). This form of religiosity allowed all the members to be an active participant in the activities (Helland, 2015); same as in the case of the group created by the Shi'a community of sector G-11.

\section{WhatsApp - road to freedom of expression}

The WhatsApp group especially dedicated to the community of G-11 is the heart of all communications that take place among them. A key feature of this application is its categorisation within 'synchronous communication', an open-ended room for discussion. Every individual may select any feature of this application to express her emotions: messages, voice notes, or even videos. Those who want to dedicate religious chants (nohas, manqabats, or soz) share their voice notes among those with whom they are not even acquainted. These women listen to these recordings and praise their efforts and contribution to the group. Many share pictures of their children on their birthday occasions, while others post events of their children's academic excellence/achievements. This technological tool even allows them to advertise their beauticians' skills among the community, with economic benefits for the provider and discount packages for the customers. But the point of difference between a regular beautician and a woman with the same skills in this group is the faith-based expression. Moreover, this faith-based group 
also becomes a virtual shop that puts clothes, accessories, and even jewellery up for display along with their rates. Special religious event(s) are often complimented by discount packages or new deal(s) in their purchase. WhatsApp provides an open arena to all the Shi'a women added based on their Shi'aIslamic faith.

Not only is virtual interaction endorsed, but the group also promotes the faith-based gatherings in their actuality. The organisers invite the women to attend the Majlis at their houses through different media. The main medium of communication among the Shi'a women community of G-11 is the WhatsApp group, named 'Kanizan-e-Um-e-Kulsum A.S', or the servants of Um-e-Kulsum. The group is named after the central Imambargah of the community, 'Bargah-e-Um e Kulsoom'. The organiser designs a message, with the topic of the Majlis as the main heading, followed by the names of the marsiya khuwan and the zakira or orator, the time and date, and the address of the house. The message ends with the name of the organiser of the majlis. Initially, there were around 66 active members of the group - an efficient platform for the women of the community to spread the message - which reaches almost all of the members of the Shi'a community residing in G-11.

Yahan pe hamara WhatsApp ka group hai, jisme hmare Imambargah ke saaray banday add hain. Issi tarha majalis ka silsila chalta rehta ha aur WhatsApp ke through aik doosre ke gharon ki majalis ka pta chalta hai. Issi tarha ham aik doosre ko btatay bhi hain

Translation: Here we have a WhatsApp group, in which all of the members of our Imambargah are added. In this way, the course of the majalis keeps moving on and we get to know about the schedule of the majalis at each other's houses through WhatsApp (Organiser 1).

The organisers make calls to the women they know and personally invite them to the majlis at their place. Apart from the women of the community of G-11, women also invite their respective family members, even those who usually live far away using the technology.

Kuch logon ko PTCL pe call karke btaya, kuch logo WhatsApp pe btaya

Translation: I informed some people by calling over PTCL ${ }^{\text {iii }}$, while the others through WhatsApp (Organiser 1, G-11/2).

\section{Majlis ke din pe phir mein unhe pick karne bhi gayi udhar jahan pehli majlis horahi thi Bargahe \\ Umme Kulsum. Wahan se kuch ladies ko apni gaari pe lekar ayi, kuch ladies ko group ke zariye, \\ WhatsApp group jo ha ham logon ka yahan ka, uske zariye inform kiya}

Translation: On the day of majlis, I went to pick the women up from the Bargah e Umme Kulsum where a majlis was already scheduled. From there, I took them with me on my car, and informed the others through the WhatsApp group we have (Organiser 2, G-11/1).

To communicate and forward the reminders for the majlis timings to the attendees, this application served with a great zeal. They delivered messages on the WhatsApp group, and requested them to come early with stress words like 'please'. A regular notice included consistent notification through messages of the organiser to remind the women of their scheduled majlis, requesting them to attend the gathering. They also made phone calls to the important women, who were either closer to them or who had to participate in the majlis.

Why this specific technological tool-WhatsApp — becomes a platform for freedom of expression is justified by the fact that the women of this faith-based group were free to express their political views as well. Despite knowing the consequences of difference in opinions, they freely expressed their points.

The development of technology has enabled people around the globe to communicate instantly through two-way voice contact, online services such as Skype, emails, and other messaging services. As explicated by Seyed Ebrahim Hosseini (2014), synchronous and asynchronous communication is actively under use by Muslim communities around the globe. Through internet, people develop online human relationship which may benefit them in terms of their businesses and daily lives (Hosseini et al., 2014).

The way WhatsApp is presently being used by this Shi'a community, CommuniTree being one of the most primitive online systems similarly became an evolutionary way to share ideas, advice(s), and all kinds of communal problem(s) in California. 'ORIGINS' became the online room for religious and spiritual discussion on a spectrum of God, holy books, life after death, to the metaphysical 
experiences and healing inquiries. It was the initial religious adaptation to the new media using text messages to portray their beliefs in drastically (trans)forming society (Helland, 2015).

\section{The other side of the coin}

While the obverse side of the coin portrays all the merits of the blend of technology and religious practises, the reverse has its own reasons to show the opposite. It is not up to us to decide whether the faith-based use of technology will only bear positive or negatives outcomes; rather the research finds both merits and demerits of this practice. The WhatsApp group of Shi'a women is also used as a medium to discuss the recent conflicts among the women in the form of voice recordings. They also tend to share common topics based on conflicting matters that propagates a strong difference in opinion(s). Furthermore, information shared on the group is not always well-referenced so as to confirm its authenticity. Although many messages have an authentic reference of a book in the end, yet many others that circulate as 'forwarded' message do not. Chances of misleading information to be shared and spread through the online group are significantly high in this case. Religious incidents of Islamic history are regularly shared, but seldom with a cross-verified reference to a book or author. Apart from religious cases, many women share political events of the past as well as the present in the same manner, giving a rise to more mythical narratives than what the truth actually is.

We know that the world we live in is rapidly transforming itself, and with it, ourselves as well. With the birth of every new generation, our societies and cultures reproduce new features, or modify the previously existing ones. In a nutshell, our society and culture are changing with the ticks of the clock. The advent of technology and new advancements in it is one example of the changing culture. Today, technology is part of every culture and day-to-day life in every household, unlike the traditional families and their indigenous lifestyles. The religious use of technology somehow transforms the religious beliefs and practices as were they realised and actualised by the older generations who did not have technology as a part of their culture. This poses a threat to the originality of the rituals, more with the free sharing of information without valid authenticity.

Existing literature have found out the negative consequences of technology in the social and moral life, particularly the religious life of a person. The research conducted by Mohammed Isah Shehu (2017) has proven how the introduction of technology has encouraged people towards freedom of expression, innovative activities, and sharing information and material that might be related to some other individual's personal life. Other factors such as misleading information, immorality and cyberbullying are also evident. Moreover, there are high chances of misrepresentation of important religious or political figures and their ideas through the online technological applications (Shehu et al., 2017).

\section{COVID-19 and Online Religion}

With the beginning of the novel Coronavirus by the end of 2019 and the declaration of the outbreak as the '2020 pandemic' on March 11, 2020 (Cucinotta \& Vanelli, 2020), countries around the world imposed nationwide lockdowns including closure of all educational and religious institutes. This called for the suspension of all sorts of social gatherings to contain the contagious disease. Pakistan officially began to observe nationwide lockdown from March 23, 2020, initially starting from the Sindh government and followed by other provinces (Faisal, 2020). Under these circumstances, the subject community made substantive use of the modern technological tools to keep their ritualistic activities intact while observing social distancing. As opposed to the initial count of 66 members before the Coronavirus outbreak, the WhatsApp group of this community expanded to 111 members. This implies a sudden shift towards technology as the pandemic called for a minimum social/physical interaction for any purpose. This shift was prompted by the Shi'a religious leaders as well, who advised the global Shi'a community to take to the online spaces for the purposes of ritualistic gatherings during the pandemic.

\section{Maujooda halaat mein agar is waba ke phelne ka khatra ho tou... Social media aur TV Channels ko} Mola Ali (a.s) ki azaadari aur taleemat nashr karne ka bharpoor zariya qarar den

Translation: During the current times, if the danger of the spread of this epidemic prevails, then... make Social media and TV Channels active fora/sources to air ritualistic activities (azaadari) and the teachings of Mola Ali (a.s) (WhatsApp message circulated as a note from Syed Muhammad Roohullah Rizvi—Shi'a scholar/orator). 
The concept of 'online majlis' was observed for the first time on the WhatsApp group of the Shi'a community. The women efficiently adapted to the new mode of interaction through organizing online meetings on various social media applications such as YouTube. Religious channels that were already operational before the pandemic were shared on the group to virtually participate in the majalis on various Islamic occasions. One such example is of a non-profit organisation 'Wisdom Gateway', established in 2009. This organization aims to spread Islamic, specifically Shi'a Islamic, information among the community worldwide through electronic media (Wisdom Gateway, 2020). During lockdowns, Wisdom Gateway's YouTube channel 'Wisdom Gateway Archive' remained active in conducting online majalis to continue with their rituals while adapting to the new lifestyle (Wisdom Gateway Archive, 2020). Other faith-based online channels remained functional not only within Pakistan but globally as well. Such channels could be accessed through the links shared in the form of a cumulative list shared within the groups. The list consisted of the venues of the majlis, the names of the speakers and organizers, and the local time of the country the gathering was conducted in. Some of the channels included in the list were "Servants of Imam Ali as", "Bibi Khadijah Academy", and "Pak Cable Network" (Servants of Imam Ali as, 2020; Bibi Khadijah Academy, 2020; Pak Cable Network, 2020). YouTube also served as a platform for conducting online International Seminars on the topic of "Objectives of Aza \& the Relevance of Azadari Rituals" that featured some of the most prominent speakers within the Shi'a sect globally. This seminar aimed to guide the community regarding the Shi'a rituals especially in the times of Covid-19 (Kauthar College for Women, 2020). It was not only aired on YouTube, but also on different Facebook pages and Web Channels ${ }^{[\mathrm{iv}]}$. The regular updates of such faithbased gatherings were circulated on the local WhatsApp group of the Shi'a community of G-11 sector. YouTube and Facebook were not the only tools used to practice online religion. Zoom is another platform that has been widely adopted for videoconferencing especially during the Covid-19 lockdowns and social distancing (Chawla, 2020). Online Zoom meetings were regularly organised on various religious topics that were mentioned along the invitation message. These messages were circulated through WhatsApp. The speakers/orators and/or reciters and the listeners participated in the online majlis during the lockdown just as they used to do so being physically there, before the Covid-19 lockdown was imposed.

A new, online culture of ritualistic activities was introduced in its full form for the first time in this local Shi'a community. This enabled the participants to explore and learn new technological applications, to access such religious gatherings anywhere in the world while staying at home, and to observe social distancing during a pandemic. Not only did they utilize YouTube, Facebook, and Zoom for such rituals but WhatsApp as well to share voice notes and videos of reciting nohas manqabats, or soz. This concept of "online majlis" is yet another living experience of keeping their religious activities intact while also observing the necessary amendments in their mode of communication. Communicative media applications have been widely adopted and substantively used by the community to promote their rituals and make the accessible even to those who either live distantly or are isolated at their homes.

The online services were enjoyed to their fullest during the Covid-19 lockdown by this religious community. However, the same online platform established solely for religious purposes proved to assist during the pandemic through constant public health updates. Special services for Covid-19 patients were being circulated to facilitate the community. During the first wave of Coronavirus, the "Imamia Oxygen Cylinder Project" was one among such emergency services that was shared for better reach to the patients. "Telemedicine Group" was another set of information circulated among the Shi' a community through faith-based online groups, to provide them with a range of health specialists during the pandemic; this requested the members to stay at home and consult the doctors through telephonic appointments. This technological tool also assisted in spreading public awareness regarding Covid-19 hotspots by sharing information about "COVID-19 Govt. PK App", a national level application developed by National Information Technology Board. Other information about the effective use of face masks and following of Standard Operating Procedures (SOPs) was recurrently posted to keep the community equipped during a public health emergency. Furthermore, special supplications recited collectively for the cure of Covid-19 were a constant observation on the group during these days. These examples of spiritual capital greatly enhanced the social networking among the women of Shi'a community of G-11, as social support was provided through faith-based technology. 


\section{Critical analysis}

As already illustrated by Helland (2016), online religion involves participatory approach to the faithbased technology with 'many-to-many communication' type. This method gave way to practise online rituals, offer prayers, and recite supplications and meditate, all through the Internet (Helland, 2016), as in the case of the present study. Lundby (2013) expresses in his theoretical study of religion and media that it is important to define religion by the means through which it is communicated, as the medium of communication largely determines the structure and shape of religion and its practices (Lundby, 2013). He further builds on a concept which was proposed by Hjarvard in 2008, i.e., 'mediatisation of religion'. According to this theory, the media is a strong pillar of the society winning its own autonomous identity that is adopted as one of the primary and basic sources of the religious beliefs, symbols, texts and rituals, consequently influencing their originality (Helland, 2016). He also argues that rituals and religious content often lose their originality when they are communicated via an Internetworked source (Helland, 2015).

In a theoretical concept introduced by Langer et al. 2006, the 'transfer of ritual' explores the matter under discussion from a perspective of the context in which the ritual has been occurring, that context or situation may be 'migration, globalisation, the information-society, world-wide integration.' (see Langer et al. 2006, p.1). Change in one or more of the aspects of the context(s)-like media, culture, society, and gender - in which a ritual is being actualised may result in the change in the internal dimension(s) of the ritual itself, some of them being transmission of ritual contents and ascribed meanings (Langer et al., 2006).

If these pre-existing concepts are applied to the present study, the Shi'a women community of sector G-11 have established an online faith-based group named after the Imam bargah of their community. Sharing of ritualistic supplications, namaz or prayers, and faith-related texts expose these traditionally valued contents to a new medium of communication that, according to the ritual transfer theory, may change the ritual or religious idea itself and take it away from its original fabric. Where this faith-based use of technology undoubtedly facilitates this community in various ways that were rarely possible in the past, the reverse of the coin also poses a great threat to the originality of these rituals (which are although intact during the majalis conducted in the Imam bargah itself, yet what is adopted through feeling virtual religion may be differently experienced and understood).

\section{CONCLUSION}

The utilisation of modern technology, especially the use of modern cellular phone applications, strengthens faith-based activities and rituals. The faith-based technology, thus, may be concluded as an important tool in producing networking among women from the same school of thought even though they belong to different social statuses, age groups and walks of life. The applications primarily not only connect but also share information related to/with the above-mentioned belief system(s). It may be concluded that the modern social media and modern cell phones in general helps bring minorities together and also gels them in a manner that is further strengthened by participating on the given or circulated information on certain platforms, hence making it a faith-based use of technology.

In an age of technology and media communication, faith and religious beliefs have experienced both their zenith and nadir when referring to its primitive content and laws. The Shi'a community of women has been noted to have endorsed the use of modern technology for the purpose of practising and spreading their religious agendas and activities. The faith-based actions of these women have taken full advantage of the contemporary technological advancements and have created their own agency with the incorporation of 'spiritual technology' in their spiritual and religious endeavours. The outbreak of Covid-19 pandemic has proved to further promote the use of technology to continue religious activities, as it has done the same in other fields such as health services, education, and the workforce. However, with the obverse comes the reverse as the other side of the same coin and may also pose a threat to the maintenance of the originality of the rituals and beliefs shared on the online platform. Nevertheless, as quoted by writer/producer J. Michael, 'Understanding is a three-edged sword: your side, their side, and the truth', it is 'time' that will eventually determine the true understanding of the faith-based use of technology. 


\section{REFERENCES}

Bibi Khadijah Academy. (n.d.) YouTube. Retrieved 9 October 2020, from https://www.youtube.com/c/BibiKhadijahAcademy

Chawla, A. (2020, May 21). Coronavirus (COVID-19) - 'Zoom' Application Boon or Bane. SSRN. Available

SSRN: https://ssrn.com/abstract=3606716 or http://dx.doi.org/10.2139/ssrn.3606716

Cucinotta D., \& Vanelli M. (2020). WHO Declares COVID-19 a Pandemic. Acta Biomed, 91(1), 157160. 10.23750/abm.v91i1.9397. PMID: 32191675

Faisal, M. (2020, March 24). Pakistan's Evolving Response to COVID-19: Inertia and structural challenges have dogged Pakistan's response. Stimson. Retrieved October 9, 2020, from https://www.stimson.org/2020/pakistans-evolving-response-to-covid-19/

Haag, S., Cummings, M., \& Dawkins, J. (1998). Management information systems for the information age. USA: McGraw-Hill, Inc.

Helland, C. (2016). Digital Religion. In D. Yamane (Ed.), Handbook of Religion and Society (pp. 177196). Springer.

Helland, C. (2015, February). Virtual Religion: A Case Study of Virtual Tibet. Retrieved June 22, 2020, from Oxford Handbooks Online: https://www.oxfordhandbooks.com/view/10.1093/oxfordhb/9780199935420.001.0001/oxfordh b-9780199935420-e-43

Hosseini, S. E., Ramchahi, A. A., \& Yusuf, R. J. (2014). The Impact of Information Technology on Islamic Behaviour. Journal of Multidisciplinary Engineering Science and Technology (JMEST) , 1 (5), 135-141.

Howarth, T. M. (2005). The Twelver Shî‘'a as a Muslim Minority in India. Routledge.

Ibahrine, M. (2014). Islam and Social Media. In K. Harvey (Ed.), Encyclopedia of Social Media and Politics (Vol. 1, pp. 736-740). SAGE Publications.

Karakas, F., Sarigollu, E., \& Kavas, M. (2015). Discourses of Collective Spirituality and Turkish Islamic Ethics: An Inquiry into Transcendence, Connectedness, and Virtuousness in Anatolian Tigers. Journal of Business Ethics, 129 (4), 811-822.

Kauthar College for Women (K.C.W). (2020, August 2). *INTERNATIONAL ONLINE SEMINAR* *Objectives of Aza \& the Relevance of Azadari Rituals*_Join us in our mission to defeat Corona and Save Azadari.*SAVE AZADARI**SAVE AZADAR*. Facebook. https://www.facebook.com/KautharCollegeForWomen/photos/a.510408305733540/315485973 4621704/?type $=3 \&$ theater

Langer, R., Lüddeckens, D., Radde, K., \& Snoek, J. (2006). Transfer of Ritual. Journal of Ritual Studies , 20 (1), 1-10.

Lundby, K. (2013). Theoretical Framework For Approaching Religion And New Media. In H. Campbell (Ed.), Digital Religion: Understand Religious Practice In New Media Worlds (pp. 225-237). London: Routledge.

Mahdi, A., \& Adamu R. (May, 2015). The Impact of Information Technology on Muslim Society [Paper presentation].

Available

at: https://www.academia.edu/12885201/THE_IMPACT_OF_INFORMATION_TECHNOLOGY _ON_MUSLIM_SOCIETY_BY_RILWANU_ADAMU_CLN_A_review_of_related_literature has_been_interrogated.

Malloch, T. R. (2010). Spiritual capital and Practical Wisdom. Journal of Management Development, $29(7 / 8), 755-759$.

https://doi.org/10.1108/02621711011059194.

McSweeney, E. (2019, December 4). Religions show faith in power of technology. Retrieved June 22, 2020, from Financial Times: https://www.ft.com/content/e002e7be-f973-11e9-a35436acbbb0d9b6

Nassar, I. A., Hayajneh, D. J., \& Almsafir, D. M. (2013). Relation between Social Network and Da'wah to Islam: A case study on Jordanian students. International Journal on Islamic Applications in Computer Science And Technology, 1 (1), 9-18.

Nisa, E. F. (2018). Social media and the birth of an Islamic social movement: ODOJ (One Day One Juz) in contemporary Indonesia. Indonesia and The Malay World, 46 (134), 24-43. 
Nurdin, N., \& Rusli, R. (November 5-8, 2012). Social Media Adoption and Use Within Indonesian Muslim Scholars: A Possibility of Adoption and Use for Da'wah Purposes [Paper presentation]. 12th Annual Conference on Islamic Studies (ACIS), Surabaya, Indonesia. Available at: https://www.researchgate.net/publication/234059493 SOCIAL MEDIA ADOPTION AND USE_WITHIN_INDONESIAN_MUSLIM_SCHOLARS_A_POSSIBILITY_OF_ADOPTION AND USE FOR DA'WAH PURPOSES.

Radde-Antweiler, K. (2008). Virtual Religion. An Approach to a Religious and Ritual Topography of Second Life. Heidelberg Journal of Religions on the Internet, 3.1, 174-211.

Saifee, A.-u.-R., Sahikh, Z. A., Sultan, S., Baloach, A. G., \& Khalid, I. (2012). The Role of Mass Media \& Information Technology in Islamic Education. European Journal of Social Sciences, 32 (13), 380 .

Servants Of Imam Ali as. (n.d.) YouTube. Retrieved 9 October 2020, from https://www.youtube.com/ServantsOfImamAli

Shehu, M. I., Othman, M. F., \& Osman, N. B. (2017). The Social Media and Islam. Sahel Analyst: Journal of Management Sciences, 15 (4), 67-80.

Vargo, D., Zhu, L., Benwell, B., \& Yan, Z. (2020, November 28). Digital technology use during COVID-19 pandemic: A rapid review. Human Behavior and Emerging Technologies, 3(1), $13-$ 24. https://doi.org/10.1002/hbe2.242

Wisdomgateway.org. (2020). Retrieved 9 October 2020, from https://wisdomgateway.org/

Wisdom Gateway Archive. (2020). YouTube. Retrieved 9 October 2020, from https://www.youtube.com/wisdomgatewayarchive

[i] An official religious mandate

[ii] The Holy Book of Islamic Religion

[iii]Pakistan Telecommunication Company Limited

[iv] The seminar could be viewed live on "Aqwal e Masoomeen", "Hyder TV", "Al-Noor TV", "Ahlabait TV" Web channels, as well as on the YouTube channels and Facebook pages of the seminar speakers themselves. 